\title{
Geological controls on focused fluid flow in the Song Hong Basin, offshore Vietnam
}

\author{
Anh Ngoc Le* \\ Hanoi University of Mining and Geology, Hanoi, Vietnam
}

ARTICLE INFO ABSTRACT

Article history:

Received 13 th Jan. 2021

Revised 19 ${ }^{\text {th }}$ Apr. 2021

Accepted 21 $1^{\text {st }}$ May 2021

\section{Keywords:}

Blow - out pipe,

Focused fluid flow,

Seepage pipe,

Song Hong Basin.
This study uses 2D seismic lines located in the central Song Hong Basin, covering an area of c. $3900 \mathrm{~m}^{2}$, in the water depth of c. $100 \mathrm{~m}$. Focused fluid flows are developed intensively and can be classified into two types: blow - out pipe and seepage pipe. They have similar seismic characteristics as a vertical zone of disturbed seismic reflections. The significant difference between them is the blow - out pipes associated with seafloor pockmarks and paleo - pockmarks which are absent in the seepage pipe. Besides, the scale of the blow - out pipe is larger, compared with the seepage pipe. The blow - out pipe is c. $500 \mathrm{~m}$ wide and $450 \div 3500$ ms TWT; the seepage pipe is smaller scale, c. $200 \mathrm{~m}$ wide and $500 \mathrm{~ms}$ TWT. Blow - out pipe is rooting from the sequence just above the diapir or deformation unit or deep lacustrine mudstones from the Late Eocene to Oligocene, and marine mudstones from the Early to Middle Miocene. The seepage pipe is rooting from the sequence above the diapir. The focused fluid flow is supposed to be controlled by the overpressured deep source layers and passive diapirism. The occurrence of focused fluid flow is an indicator for the active petroleum system in the study area. Intensive development of focused fluid flow proves a great hydrocarbon potential in the Song Hong basin.

Copyright (C) 2021 Hanoi University of Mining and Geology. All rights reserved.

\section{Introduction}

Focused fluid migration in marine sediments is a widespread phenomenon that is increasingly gaining attention in the context of environmental discussions (Berndt, 2005). However, direct observations of hydrocarbon leakages are difficult

${ }^{*}$ Corresponding author

E - mail: lengocanh@humg.edu.vn

DOI: 10.46326/JMES.2021.62(3).05 for the obvious reason that they take place below the Earth's surface (Løseth et al., 2011). Evidence of the active leakage of hydrocarbon and associated formation water is, therefore, most commonly found on the surface, seafloor, or in seawater (Cartwright et al., 2007; Løseth et al., 2011), while remnants of subsurface paleo leakage anomalies may be found in the outcrops (Parnell and Kelly, 2003).

Focused fluid flow or pipe can best be defined seismically as columnar zones of disturbed 
reflections that may or may not be associated with sub - vertically stacked amplitude anomalies. Before, these features are commonly ignored on seismic data because they tend to exhibit a vertical to sub - vertical geometry and can therefore be confused with seismic artifacts such as migration anomalies, scattering artifacts (Løseth et al., 2011). Therefore, care is needed in differentiating true pipes from seismic artifacts, which is best done by considering the structural and stratigraphic context of any probable pipe (Løseth et al., 2011).

Cartwright et al. (2007) introduced the term seal bypass system, including pipes, mud volcanoes, sand injections, and gas chimneys. High fluid overpressure opening a hydrofracture

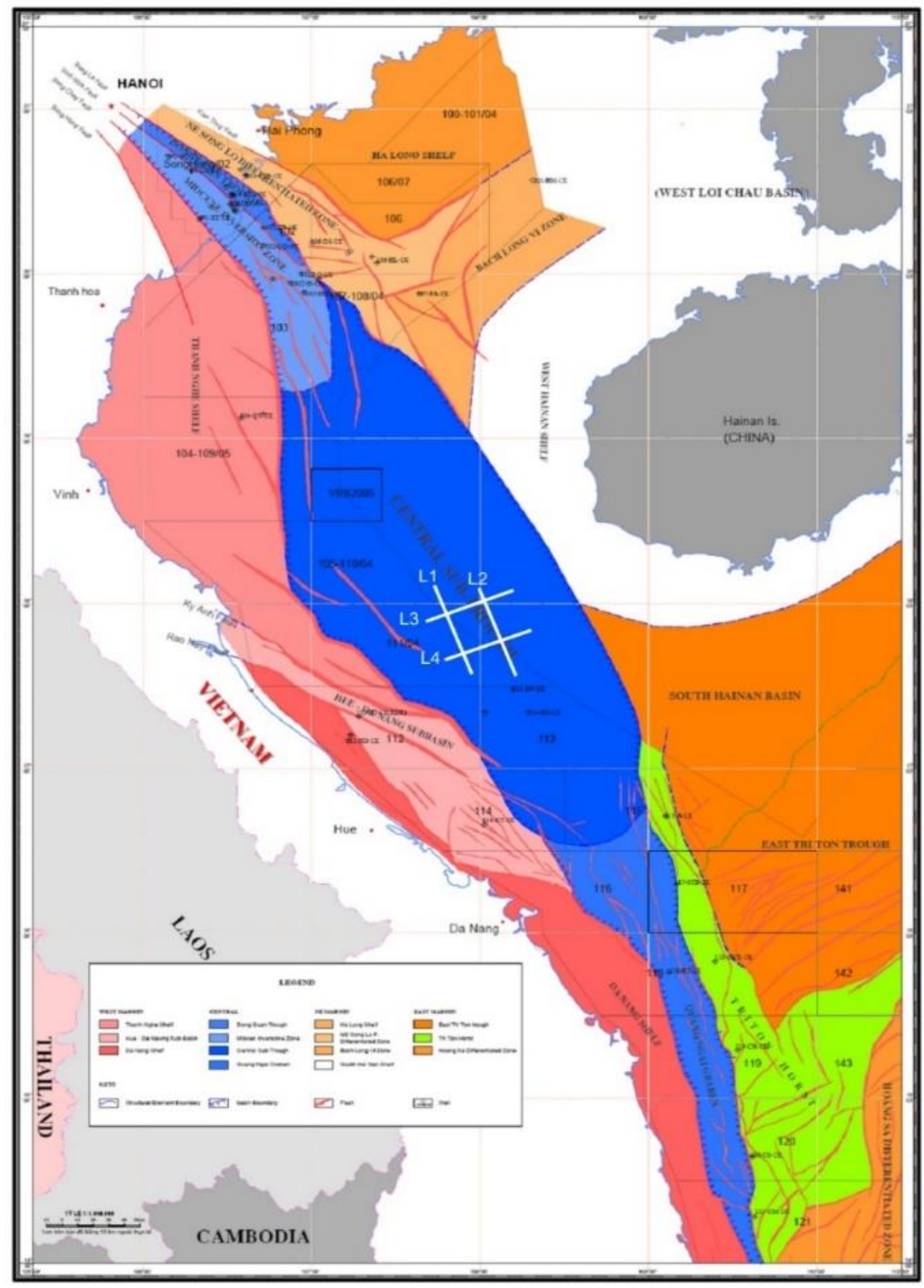

Figure 1. Structural elements map of the Song Hong Basin (Nguyen - Hiep, 2019) and the location of the study area, indicated by four $2 D$ seismic lines, marked from $L 1$ to L4, covering an area of $3900 \mathrm{~km}^{2}$. 
through low permeable sediments is a common first phase of all these bypass structures.

The Song Hong Basin is a northwest trending transform extension basin, which began to develop in Mesozoic times on the passive continental margin of Vietnam (Figure 1) (Rangin et al., 1995; Zhenfeng and Baojia, 2008). Previous studies based on 2D and 3D multichannel seismic data have documented the occurrence of submarine gas seeps, focused fluid flow/pipe within the Song Hong Basin. However, the characteristic and occurrence of focused fluid flow are still limited. This paper presents a study of pipes from the central Song Hong Basin, describes the detail of the seismic pipe anomalies and investigates the geological controls on pipe distribution.

\section{Focused fluid flows}

The detailed structure of focused fluid flow is poorly understood at present and may be highly variable. In some cases, focused fluid flows consist of zones of deformed reflections related to minor folding and faulting. In others, they appear to consist of stacked pockmark craters or stacked localized amplitude anomalies that are likely to be small gas accumulations or zones of cementation but with no resolvable deformation (Cartwright et al., 2007) (Figure 2). According to these authors, there are four types of pipes, dissolution pipes, hydrothermal pipes, blow - out pipes, and seepage pipes. The latter two are closely related and can be distinguished by the presence or absence of surface features denoting a more dynamic flow
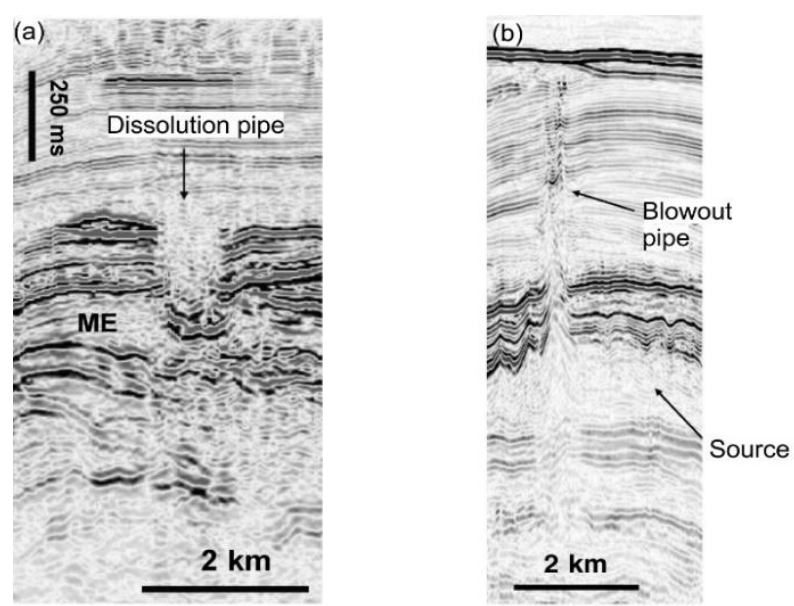

regime along the pipe (Figure 2).

Dissolution pipes form by rock dissolution occurring at depth to form subsurface cavities that promote instability in the overburden leading to collapse (Cooper, 1986) (Figure 2a). Thus, this type of pipe probable to occur in areas of evaporite or carbonate karst (Cartwright et al., 2007).

Hydrothermal pipes form by the release of a high flux of hydrothermal fluids associated with certain kinds of igneous intrusions, particularly mafic sills or laccoliths (Svensen et al., 2004) (Figure 2c). The volumes of fluids involved depend primarily on magma composition, temperature, and intrusive volume (Delaney, 1987).

Blow - out pipes are the most enigmatic and most difficult to classify. The pipes are typically seen on seismic data as a columnar zone of disturbed reflections or vertically stacked localized amplitude anomalies (Figure 2b). They can be distinguished by their association with surface or paleo - pockmarks, small faults, and folds occurrence either on the margins of columnar disturbance or within the core of the column (Løseth et al., 2011; Anka et al., 2012).

Seepage pipes are like blow - out pipes in their seismic character and dimensions but lack the blow - out craters diagnostic of a violent outburst of fluid at the upper pipe termination (Figure 2d). Seepage pipes tend to form in similar settings to blow - out pipes, i.e., above gas reservoirs, on structural crests, and along updip margins of aquifers. The main difference between seepage

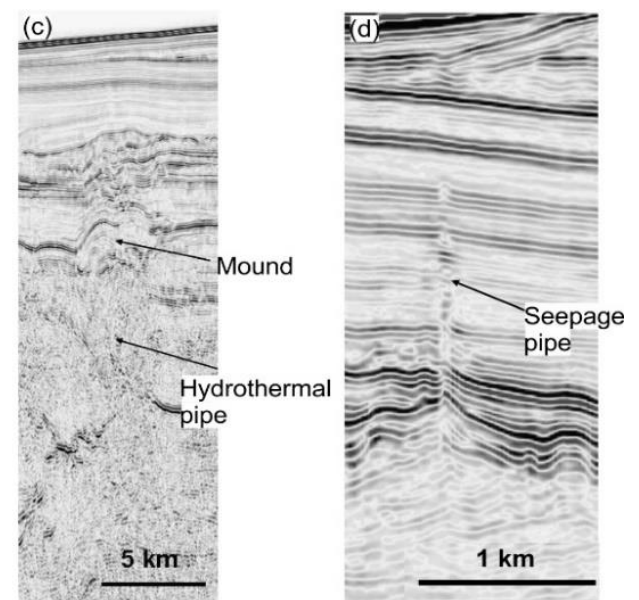

Figure 2. Seismic expressions of different pipes crossing sequences. (a) dissolution pipe, (b) blowout pipe, (c) hydrothermal pipe, (d) seepage pipe (Cartwright et al., 2007). 
and blow - out pipes appears to be the physical properties of the host rock. Blow - out pipes occur almost exclusively in fine - grained sealing sequences, whereas seepage pipes appear to occur in sand or silt - dominated sequences (Cartwright et al., 2007).

An example of outcrops of blow - out pipes from Rhodes, Greece is shown in Figure 3, proving that vertical pipes form in relatively soft clays. Seismic modeling of an up - scaled $50 \mathrm{~m}$ wide pipe, which is filled with structureless material, proves to be similar to the seismic pipe anomalies offshore Nigeria (Løseth et al., 2011).

\section{Dataset and methodology}

The study purely used 2D seismic data in the offshore Song Hong Basin (from line 1 to line 4), covering an area of $3900 \mathrm{~km}^{2}$ (Figure 3 ). The area is located at a water depth of $100 \mathrm{~m}$. The study interval ranges from Miocene to Pleistocene in age with a record time of $6.0 \mathrm{~s}$ Two Way Time (TWT). The seismic data is zero - phase and displayed in contrast color mode.
The analysis focuses on fluid flows. The interpretation of the seismic data has primarily used the Schlumberger ${ }^{\mathrm{TM}}$ Petrel software. Because of the amplitude variation and discontinuous character of the focused fluid flow bodies, this vertical zone is, therefore, best detected in the chaos/RMS attribute, allowing to individualize the focused fluid flows from the substrate. Due to the lack of well data in the basin, the vertical depth will be quoted in two - way time.

\section{Results}

Seismic interpretation reveals the occurrence of focused fluid flows in the central Song Hong Basin. They are in general characterized as vertical zones with distorted seismic reflections, which are recognized below the seafloor craters (Figures 4, 5). In the distorted zone, various seismic reflection patterns are observed, from minor folding (Figure 6) to appear to consist of stacked paleo - pockmarks or dimmed reflections with variable continuity (Figures $4 \div 6$ ).

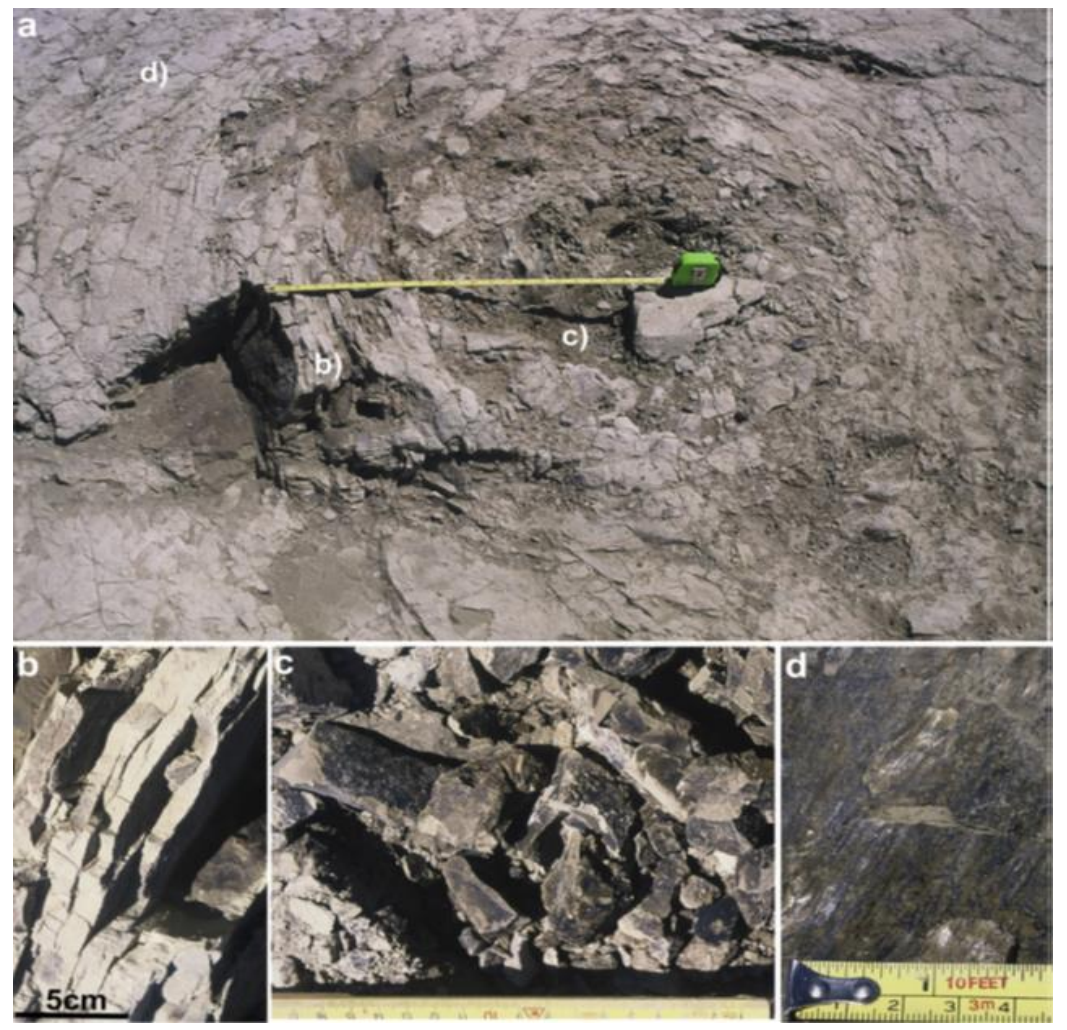

Figure 3. (a) Exposed pipe structure observed in the outcrop. The yellow measuring tape is $60 \mathrm{~cm}$ long. (b) The rim of the pipe is strongly sheared. When the center of the pipe (c) was breaked out it comprised angular clasts with black coating. The fractures surrounding the pipe commonly have slickensides (d) 

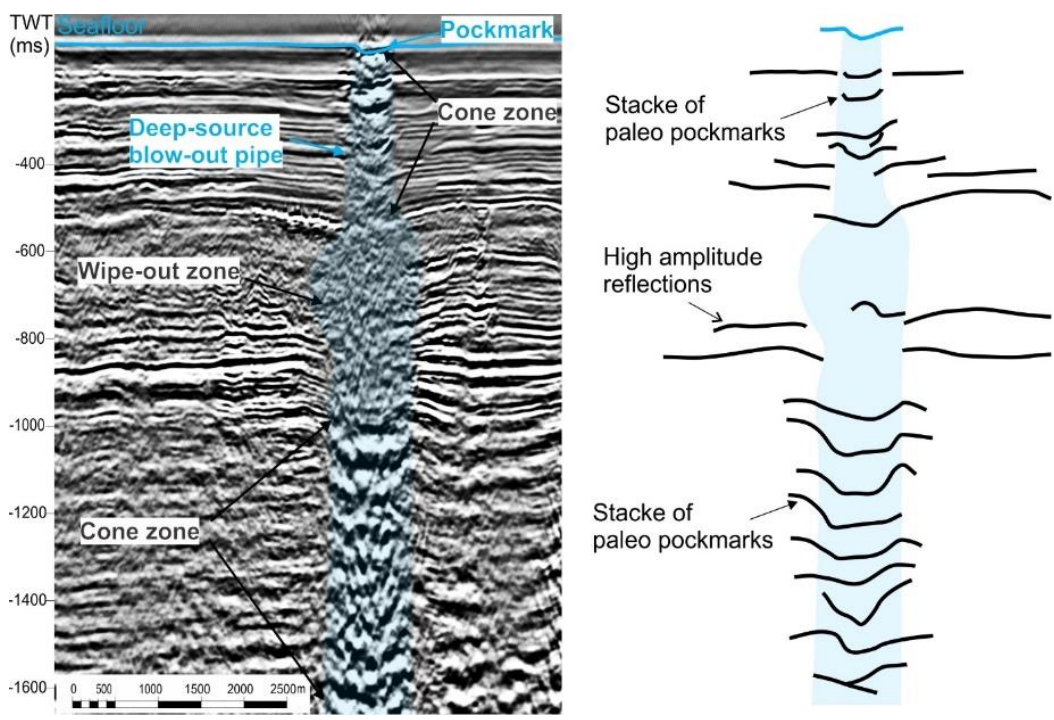

Figure 4. Seismic expression of blow - out pipe observed in line 3. This seismic profile showing vertically stacked paleo - pockmarks (cone zone) proving for longevity of blowout pipe activity. This blow - out pipe is rooting from a deep Oligocene overpressured unit.
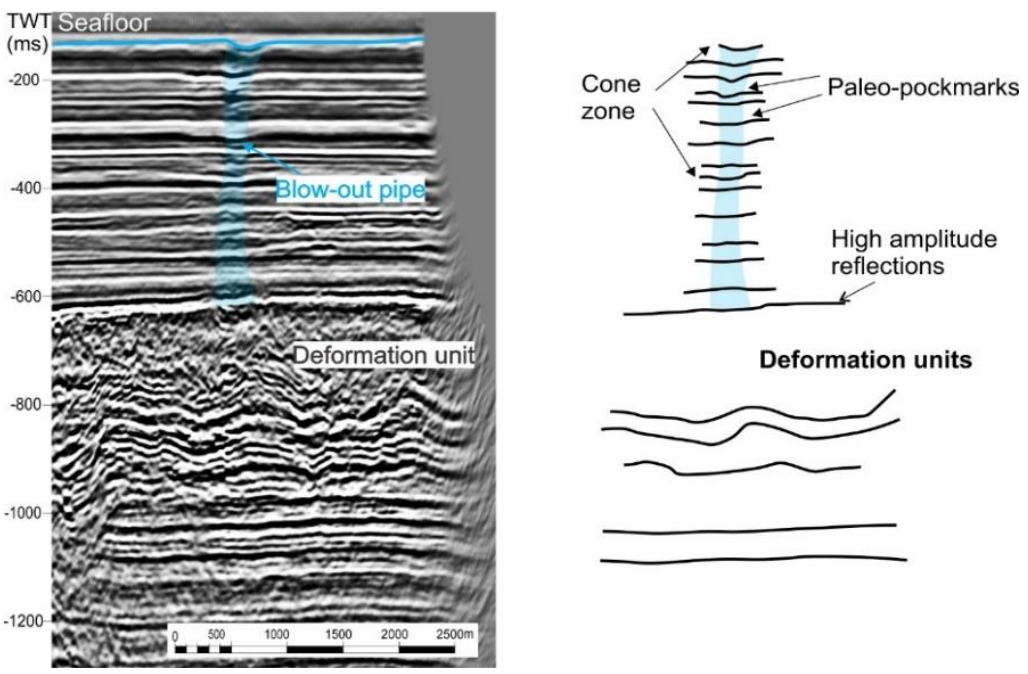

Figure 5. Seismic expression of blow - out pipe in line 1. This seismic profile showing vertically stacked pockmarks in the upper pipe. This shallow blow - out pipe is rooting from the high deformation unit.

\subsection{Blow - out pipes}

Most of the pipes observed in the study area are classified as blow - out pipes. The significant difference between the blow - out pipes and seepage pipes is the occurrence of surface pockmarks and stacked paleo - pockmarks (Figures 4, 5). The observation of modern pockmark and paleo - pockmarks associated with a pipe leading the interpretation of blow - out pipe in the area. The pipes have a deep source, high energy, large scale or shallow source, lower energy, and smaller scale.

Deep - sourced pipe is characterized as a vertical column of highly disturbed reflections (Figures 4 \& 7). Local deformation of reflections is observed in the upper pipe and lower pipe. These are interpreted to be paleo - stacked pockmarks. The pipe created a crater on the seafloor; craters are about $10 \div 15 \mathrm{~m}$. They are underlain by interpreted cones and seismic pipe anomalies that can be traced down to deep source zones at 3500 ms TWT below the seafloor. The seismic pipe anomalies are $500 \div 1600 \mathrm{~m}$ wide and almost. 


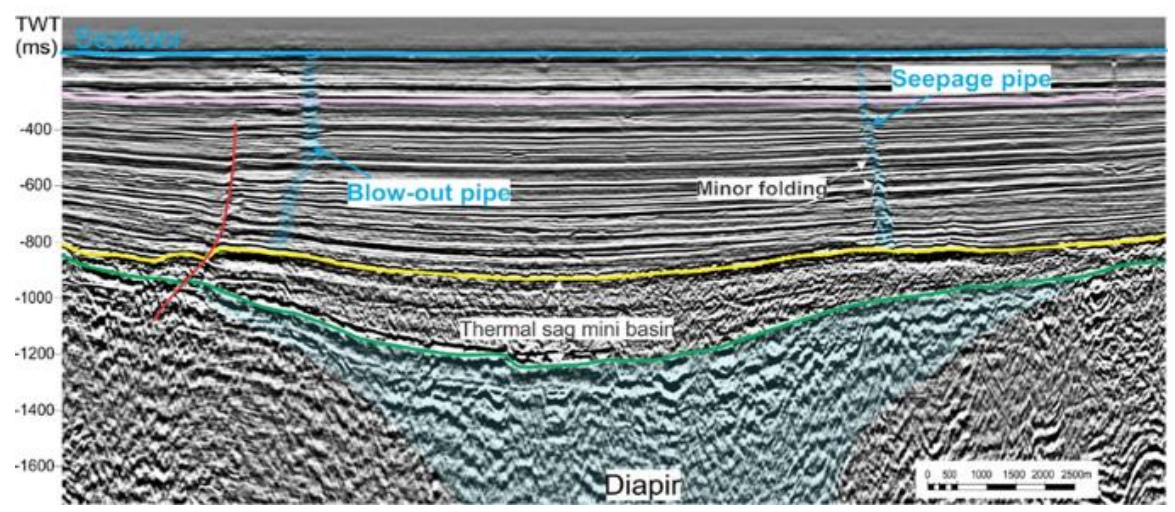

Figure 6. Seismic expression of seepage pipe and blow - out pipe in line 3. Seepage pipe appears as columnar zones of disrupted reflections with localized amplitude anomalies. The pipe derives from a small fold on the lower section. The lack of any pockmark located at the upper termination of the pipe suggests low fluid flux and possible seepage.
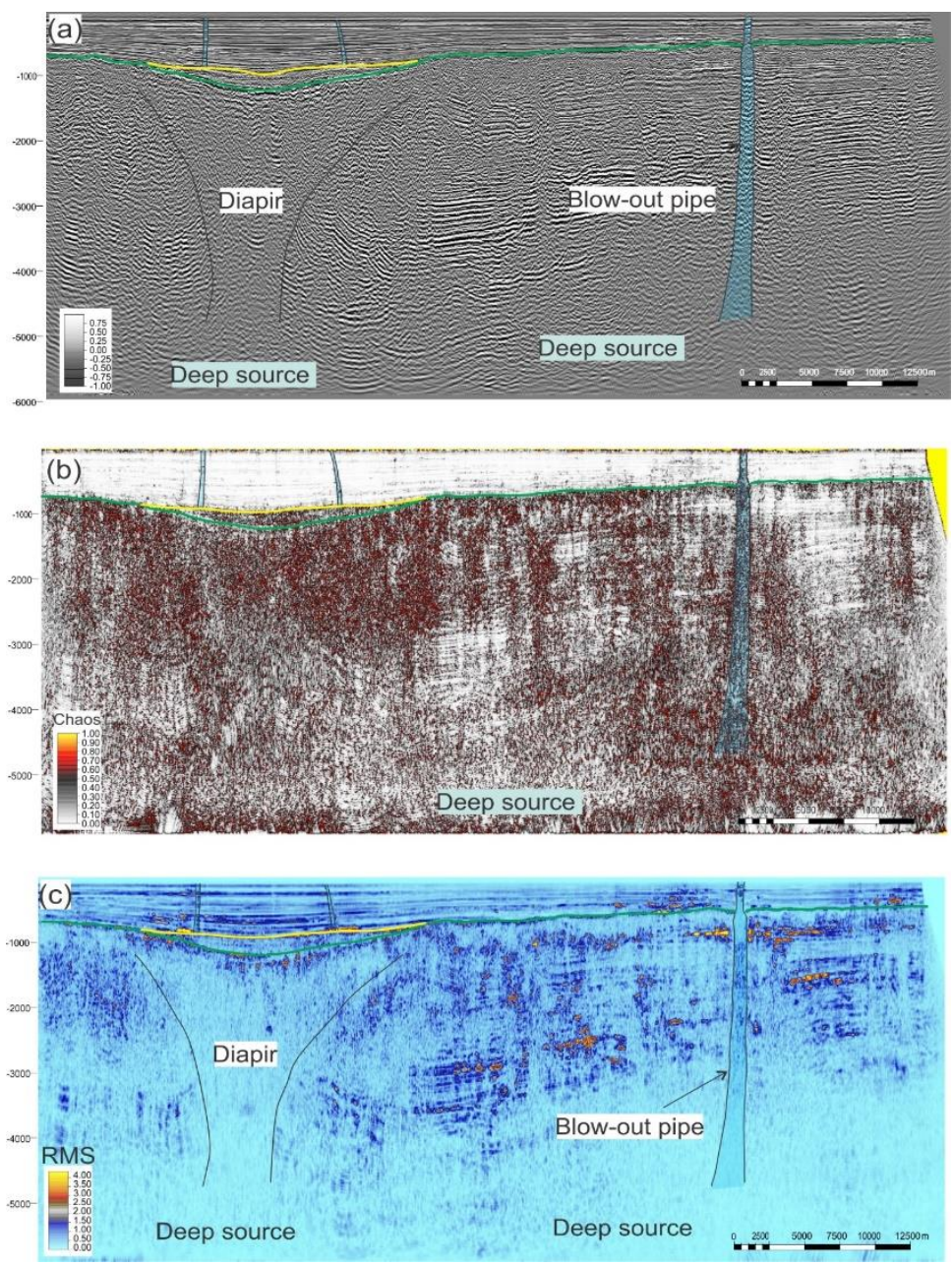

Figure 7. (a) A full seismic line (line 3) expressed of focused fluid flows and a diapir. The blow - out pipes have deep source in Oligocene/Miocene sequence; (b) Chaos amplitude attribute of line 3; (c) RMS attribute of line 3. The diapir seems to reveal better in the RMS than Chaos attribute. In the Chaos attribute the boundary of diapir is hard to be detected. 
vertical. This blow - out pipe roots from deep lacustrine mudstones from the Late Eocene to Oligocene, and marine mudstones from the Early to Middle Miocene

A shallow - sourced pipe is observed as a vertical zone, characterized as disturbed seismic reflections (Figures 5, 6). The pipe terminated on the seafloor in form of a pockmark. Underlying the seafloor pockmark is stacked of paleo pockmarks which are dominated on the upper part of the pipe, giving the confidence for the interpretation of blow - out pipe. This pipe has a smaller scale compared with the deep source pipe. The pipe is about $400 \mathrm{~m}$ wide and $450 \mathrm{~ms}$ TWT long, rooting from the high deformation unit in Pliocene.

\subsection{Seepage pipes}

Seepage pipe is distributed above the deformation unit (Figure 6). The pipe has a similar form to the blow - out pipe. The pipe is defined seismically as a columnar zone of disturbing reflections, except small folded reflections observed at the lower pipe. It is about $200 \mathrm{~m}$ wide and $500 \mathrm{~ms}$ TWT long. There is no clear image of the crater on the seafloor at the pipe termination and also the paleo - pockmarks along the pipe. This indicates the lack of blow - out craters diagnosing an explosion of fluid at the upper pipe termination. This pipe, therefore, is defined as a seepage pipe.

The pipe is rooting from the thermal sag unit just above the diapir. Diapir acts as the main conduit for the upward movement of fluids released from the deep high - pressure system (Figure 7). Abnormally high pressure provides a significant driving force for gas migration (Zhenfeng and Baojia, 2008). The diapir is in the passive phase creating a thermal sag mini basin above the diapir, with a total thickness of $300 \mathrm{~ms}$ TWT. The remaining high pressure in the core of the diapir is transferred to the thermal sag sequence, resulting in the leaking fluid and creating the seepage pipe observed above the diapir.

\section{Discussion}

Overpressured fluid, generated from the combined factors of under compaction, hydrocarbon generation, hydrothermal pressurization, and tectonic compression, is the driving force of the evolution of diapir (Wan et al., 2019). Blow - out pipes tend to be localized at natural leakoff points for overpressured pore fluids, for example, at the crests of structures, above gas reservoirs, or at the updip limits of aquifers (Cartwright et al., 2007). The genetic process of a high - pressure gradient drives the fluid flow in such a violent way as to produce the columnar conduit. The distribution of the focused fluid flow is related to the overpressure in the muddy sequence of Oligocene and Miocene age and associated with the diapir occurrence. Kilometer scale focused fluid flow roots directly from the overpressured layer in the deep section, piercing the upper sequence. Its termination created a seafloor pockmark. In addition, hundred - meter scale focused fluid flows are developed from the top of the diapir as a result of passive diapirism. The distribution of mud diapir is possibly related to the population of the focused fluid flows. Mud diapir was intensively developed in the central Song Hong Basin and documented in both Vietnam and China parts (Wan et al., 2015; Zhenfeng and Baojia, 2008; Nguyen - Hiep, 2019; Le and Ha, 2020; Le, 2021).

The blow - out pipes in the area has two sources. They are either rooting from a deep source or a shallow source. The deep source blow - out pipe has much larger scale compared with the shallow blow - out pipe. It roots from the same source with the diapir in the area and thus has high energy to form large-size blow - out pipe. The shallow source blow - out pipe developed above the diapir, as a result of passive phase of diapism thus has much lower energy, resulting in small scale pipes. However, the occurrence of seepage pipes above the diapir indicates the unequal energy distribution of the diapir itself below.

In the study area, the seismic characteristics of the pipes and also associated geological feature indicate the existence of blow - out pipes and seepage pipes. The shallow pipes developed from the late Miocene to Pleistocene. There is no carbonate or evaporate in these sequences; therefore, there is no chance to procedure the dissolution pipes. Moreover, the deep - source pipe is rooting directly from the Oligocene/Miocene sediments; thus, this pipe has 
no relationship with magma composition, and it is impossible to be the hydrothermal pipe.

The occurrence of focused fluid flows is considered to be associated with hydrocarbon generation, thus, suggests the active petroleum system in the study area. This possibly produces a commercial reserve for the area. This interpretation is supported by the occurrence of an active petroleum system discovered in the part of China. The Dongfang 1 - 1 (DF1 - 1) mud diapir field is the largest gas field discovered in the Song Hong basin up to now (Zhenfeng and Baojia, 2008). The distribution of focused fluid flows in the study area suggested its relationship with the overpressured layer in the deeper part and the occurrence of diapir in the area.

\section{Conclusions}

Focused fluid flows in the central Song Hong basin are developed intensively at different scales. There are two types of focused fluid flows, including blow - out pipes and seepage pipes. The blow - out pipes are rooting from either a deep source or shallow source; meanwhile, the seepage pipe is rooting from the shallow one. Blow - out pipes are terminated on the seafloor in form of seafloor pockmarks at about $500 \mathrm{~m}$ wide and 450 to $3500 \mathrm{~ms}$ TWT. It is characterized as stacked of paleo - pockmarks along the pipe or dominantly in the upper part of the pipe. Seepage pipe is a smaller scale, c. $200 \mathrm{~m}$ wide and $500 \mathrm{~ms}$ TWT, characterized as a disturbed zone with minor folding at the low part of the pipe. The occurrence of focused fluid flows indicates an active petroleum system which proves a great hydrocarbon potential in the study area, and groups are as different as possible from others.

\section{Author contributions}

The author contributes $100 \%$ to the article.

\section{References}

Anka, Z., Berndt, C. \& Gay, A. (2012). Hydrocarbon leakage through focused fluid flow systems in continental margins. Elsevier.

Berndt, C. (2005). Focused fluid flow in passive continental margins. Philosophical Transactions of the Royal Society A:
Mathematical, Physical and Engineering Sciences, 363, 2855 - 2871.

Cartwright, J., Huuse, M. \& Aplin, A. (2007). Seal bypass systems. AAPG Bulletin, 91, 1141 - 1166.

Cooper, A. (1986). Subsidence and foundering of strata caused by the dissolution of Permian gypsum in the Ripon and Bedale areas, North Yorkshire. Geological Society, London, Special Publications, 22. 127 - 139.

Delaney, P., (1987). Heat transfer during emplacementand cooling of mafic dykes. Mafic dyke swarms, 34, 31 - 46.

Løseth, H., Wensaas, L., Arntsen, B., Hanken, N. M., Basire, C. \& Graue, K. (2011). 1000 m long gas blow - out pipes. Marine and Petroleum Geology, 28, 1047 - 1060.

Le, A. N. \& Ha, M. Q. (2020). Interpretation of mud diapirs using 2D seismic attributes and Unsupervised Neural Network: A case study of the Song Hong Basin. In: BUI, N. X. (ed.) Earth Sciences and Natural resources for sustainable development (ERSD2020) Conference.

Le, A. N. (2021). Seismic Characteristics of Mud Diapir in Song Hong Basin, offshore Vietnam. Iraqi Geological Journal (IGJ), 54(1F).

Nguyen - Hiep. (2019). The Petroleum Geology and Resources of Vietnam. Science and Technics Publishing House.

Parnell, J. \& Kelly, J. (2003). Remobilization of sand from consolidated sandstones: evidence from mixed bitumen - sand intrusions. Geological Society, London. Special Publications, 216, 505 - 513.

Rangin, C., Klein, M., Roques, D. \& Le Pichón, X., (1995). The Red River fault system in the Tonkin Gulf, Vietnam. Tectonophysics, 243, 209 $-222$.

Svensen, H., Planke, S., Malthe - Sørenssen, A., Jamtveit, B., Myklebust, R., Eidem, T. R. \& Rey, S. S. (2004). Release of methane from a volcanic basin as a mechanism for initial Eocene global warming. Nature, 429, 542 545. 
Wan, Z., Shi, Q., Zhang, Q., Cai, S. \& Xia, B., (2015). Characteristics and developmental mechanisms of mud volcanoes on the southern margin of the Junggar Basin, NW China. Geological Journal, 50. 434 - 445.

Wan, Z., Yao, Y., Chen, K., Zhong, S., Xia, B. \& Sun, Y., (2019). Characterization of mud volcanoes in the northern Zhongjiannan Basin, Western South China Sea. Geological Journal, 54. 177 189.

Zhenfeng, W. \& Baojia, H., (2008). Dongfang 1 - 1 gas field in the mud diapir belt of the Yinggehai Basin, South China Sea. Marine and Petroleum Geology, 25. 445 - 455. 